\title{
METODE: MEMBALIK KELAS, KOLABORATIF, KREATIVITAS SISWA (MODERASI) PELAJARAN EKONOMI DI SMA NEGERI 3 YOGYAKARTA
}

\author{
Oleh: Muhamad Nanang Rifa'i ${ }^{1}$, Khafid Ismail ${ }^{2}$, Miftahur Rohmah ${ }^{3}$, \\ Rusmiati $^{4}$ \\ nanang@stkipnurulhuda.ac.id ${ }^{1}, \underline{\text { khafid@ } @ \text { stkipnurulhuda.ac.id }}{ }^{2}$, \\ rohmah@stkipnurulhuda.ac.id ${ }^{3}$, rusmiati@stkipnurulhuda.ac.id ${ }^{4}$, \\ (Program Studi Pendidikan Ekonomi, STKIP Nurul Huda)
}

\begin{abstract}
Abstrak-Pembelajaran kolaboratif siswa diyakini penting untuk hasil belajar mereka. Seorang siswa dengan kemampuan kreativitas belajar yang lebih baik mungkin memiliki prestasi belajar yang lebih baik. Namun konteks yang berbeda mempromosikan berbagai tingkat pencapaian. Oleh karena itu penelitian ini menyelidiki tentang metode membalikkan kelas pada bentuk pembelajaran kolaboratif dan kreativitas menjadi moderasi dalam penelitian ini. Siswa sekolah SMA Negeri 3 Yogyakarta menjadi sampel dalam penelitian ini sebanyak 117 siswa. Metode yang digunakan dalam penelitian ini yaitu kuantitatif dengan menggunakan pendekatan moderasi atau analisis moderasi. Hasil penelitian menunjukkan bahwa siswa dengan kemampuan kreativitas dapat meningkatkan metode membalikkan kelas pada bentuk pembelajaran kolaboratif dalam kursus ekonomi. Dengan demikian penelitian ini berkontribusi pada pendekatan konseptual model pengajaran untuk kursus ekonomi.
\end{abstract}

Kata Kunci: Kreativitas Siswa, Membalik Kelas, dan Kolaboratif.

Abstract-Students' collaborative learning is believed to be important to their learning outcomes. A student with better learning creativity ability may have better learning achievement. Yet different contexts promote different levels of attainment. Therefore, this study investigates the method of reversing the classroom in the form of collaborative learning and creativity is the moderation in this study. Students of SMA Negeri 3 Yogyakarta became the sample in this study as many as 117 students. The method used in this research is quantitative by using a moderation approach or analysis of moderation. The results showed that students with creative abilities could improve the class-reversing method in the form of collaborative learning in economics courses. Thus this research contributes to a conceptual approach to teaching models for economics courses.

Keywords: Creativity, Flipping Classroom and Collaborative.

\section{PENDAHULUAN}

Dalam pengajaran ekonomi pembelajaran tradisional masih mengambil porsi terbesar dari waktu kelas diperkirakan $60 \%$ berbanding 40\% (Watts \& Schaur, 2011) Peran sentral dari pembelajaran berada di bawah pengawasan yang meningkat 
karena bukti empiris menunjukkan teknik pembelajaran aktif lebih efektif daripada ceramah dalam mempromosikan pembelajaran (Freeman et al., 2014). Pendekatan pedagogis yang mengurangi pembelajaran tradisional menjadikan bebaskan waktu kelas untuk pembelajaran aktif merupakan ruang kelas terbalik (flipping classroom). Kelas terbalik tampaknya meningkatkan hasil belajar seperti yang dilaporkan dalam tiga ulasan utama literaturs yang ada (Bishop \& Verleger, 2013) \& (O'Flaherty et al., 2015).

Dalam studi ini, peneliti mengeksplorasi lebih lanjut pertanyaan yang diajukan oleh (Jensen et al., 2015) \& (Ryan \& Reid, 2015) serta membandingkan hasilnya mata kuliah prinsip mikroekonomi berbasis kuliah yang memanfaatkan teknik pembelajaran aktif dengan dua desain mata kuliah yang dibalik. Fokus pertanyaan penelitian ini adalah : (1) Bagaimana kedua desain kursus terbalik mempengaruhi hasil pembelajaran dan dibandingkan dengan kursus pembelajaran aktif yang tidak dibalik. (2) Bagaimana pengaruh kedua desain kursus terbalik tersebut terhadap evaluasi pembelajaran dan pengajaran yang dirasakan siswa (kepuasan, beban kerja,kesulitan yang dirasakan) dibandingkan dengan kursus pembelajaran aktif yang tidak dibalik?
Kami menggunakan model regresi linier berganda dan regresi logistik biner serta statistik nonparametrik untuk menguji ini dampak. Biaya pembalik kelas juga dibahas secara singkat. Kursus ini dirancang ulang sebagai ruang kelas yang dibalik dan yang terkait Hasil belajar di analisis mengikuti pendekatan desain berbasis penelitian. Penelitian berbasis desain terintegrasi penelitian pendidikan empiris dengan desain pengaturan pembelajaran yang digerakkan oleh teori. Jika berfokus pada bagaimana menerapkan praktik pedagogis dalam konteks pendidikan otentik, dan secara bersamaan mengembangkan wawasan teoritis baru. Khusus untuk penelitian berbasis desain adalah memasukkan fase penelitian dan desain yang berurutan dan berulang: desain pendidikan pengaturan didasarkan pada model dan teori sebelumnya dan hasil digunakan untuk mengembangkan teori dan implementasi yang berurutan dari metode pedagogis.

Metode pembelajaran kolaboratif dituntut adanya pembaharuan dalam segi metode belajar yang mencangkup berbagai aspek mulai dari sosialisasi siswa sampai dari kerjasama untuk menyelesaikan tugas siswa dengan siswa lain.

Dengan adanya kolaboratif, para peserta didik dapat belajar berbicara dengan baik antar sesama manusia, serta siswa dapat 
menerapkan toleransi, bersikap kritis dan memupuk kerjasama (Hosnan, 2014).

Realita di lapangan masih banyaknya guru menggunakan metode pengajaran yang melibatkan siswa sehingga kurang partisipasinya peserta didik dalam kegiatan belajar mengajar terkesan berkesan siswa cepat bosan akan pembelajaran yang disampaikan. Akibatnya akan berpengaruh pada nilai atau hasil belajar siswa yang masih dibawah nilai KKM yang telah ditentukan menurut hasil wawancara dengan para siswa sekolah SMA 3 Yogyakarta mengatakan bahwa pembelajaran ekonomi di kelasnya sangat membosankan walaupun itu teori ekonomi. mereka juga mengatakan metode pengajaran yang digunakan masih monoton atau menggunakan satu metode pengajaran yaitu metode ceramah. seorang pendidik pemilihan metode pembelajaran merupakan sebuah cara untuk menyelesaikan masalah seperti contoh masalah yang terjadi di atas.

Pembelajaran kolaboratif memiliki tiga karakter secara umum, yaitu adanya perubahan hubungan antara guru dan siswa adanya pendekatan baru dalam hal pengajaran oleh guru, dan komposisi pembelajaran kolaboratif.

Pembelajaran, antara guru dan siswa saling berbagi pengalaman yang bisa dijadikan pengetahuan dalam pembelajaran yang akan dilaksanakan. Guru dan siswa saling berbagi otoritas serta terbentuknya kelompok siswa yang heterogen. menggunakan teknik dan metode belajar yang tepat memungkinkan siswa lebih aktif belajar, karena sesuai dengan gaya belajar siswa.

Pengetahuan didistribusikan di antara orang dan lingkungan, yang mencakup objek, artefak, alat, buku, dan komunitas dimana orang berada. Ini menunjukkan bahwa memperoleh pengetahuan dapat dicapai dengan baik melalui interaksi dengan orang lain dalam kegiatan bersama. memandang bahwa pengetahuan dikonstruksi secara kolaboratif antar individu dan keadaan tersebut dapat disesuaikan oleh setiap individu. Salah satu model pembelajaran yang dapat digunakan adalah model pembelajaran kolaboratif.

Model pembelajaran kolaboratif merupakan model pembelajaran dimana siswa saling bekerja sama dalam kelompokkelompok kecil untuk mencapai pemahaman dan tujuan pembelajaran.

Pembelajaran kolaboratif (collaborative learning) merupakan suatu istilah (umbrella term) yang mencakup banyak bentuk pembelajaran kolaboratif, mulai dari proyek kelompok kecil hingga bentuk kerja kelompok yang lebih spesifik yang disebut cooperative learning. Pembelajaran model kolaboratif diharapkan mampu mewadahi untuk siswa belajar 
tentang komunikasi dan bekerjasama dengan baik.

Pembelajaran kolaborasi sangat dianggap perlu untuk diaplikasikan di sekolah SMP sampai SMA sederajat. Cara-cara media pembelajaran kolaborasi ini lebih bergerak para siswa untuk aktif dan interaktif serta bekerjasama dalam menyelesaikan tugas-tugas akademik di kelas. Dengan demikian, pembelajaran kolaborasi secara fundamental berbeda dengan pendekatan konvensional-tradisional yang selama ini dilakukan, yang lebih "direct-transfer" atau "oneway transmission" model. Dalam hal ini siswa menjadi satu-satunya sumber pengetahuan atau keterampilan. Pembelajaran kolaborasi lebih memandang proses pembelajaran sebagai "learnercentered" dan bukan, "teacher centered". Pengetahuan dipandang sebagai suatu konstruk sosial, difasilitasi melalui interaksi antar kelompok sebaya, evaluasi dan kooperasi. Oleh sebab itu, peran pembelajaran berubah dari penyampai informasi (transferring knowledge), "the stage on the stage" menjadi seorang fasilitator dalam diri pebelajar untuk mengkonstruksi pengetahuannya, "the guide on the side". "on the stage" menjadi seorang fasilitator dalam diri pebelajar untuk mengkonstruksi pengetahuannya, "the guide on the side" (Sudrajat, 2020) .
Enam karakter dasar masingmasing, yaitu: (1) tujuan kelompok (group goals), (2) tanggung jawab individual

(individual accountability), (3) kesempatan yang sama untuk mencapai keberhasilan (equal opportunities for success), (4) kompetisi antar kelompok (team competition), (5) pengkhususan tugas (task specialization); dan (6) adaptasi terhadap kebutuhan individu (adaptation to individual needs), berikut ini langkah-langkah pembelajaran kolaboratif. 1) Para siswa dalam kelompok menetapkan tujuan belajar dan membagi tugas sendiri-sendiri 2) Semua siswa dalam kelompok membaca, berdiskusi, dan menulis. 3) Kelompok kolaboratif bekerja secara bersinergi mengidentifikasi,

mendemonstrasikan, meneliti, menganalisis, dan memformulasikan jawaban tugas atau masalah dalam LKS atau masalah yang ditemukan sendiri. 4) Setelah kelompok kolaboratif menyepakati hasil pemecahan masalah kemudian masing-masing siswa menulis laporan sendiri-sendiri secara lengkap. 5) Guru menunjuk salah satu kelompok secara acak (selanjutnya diupayakan agar semua kelompok dapat giliran ke depan) untuk melakukan presentasi hasil diskusi kelompok kolaboratifnya di depan kelas, siswa pada kelompok lain mengamati, mencermati, membandingkan hasil presentasi tersebut, dan menanggapi. Kegiatan 
ini dilakukan selama lebih kurang 20-30 menit. 6) Masing-masing siswa dalam kelompok kolaboratif melakukan elaborasi, inferensi, dan revisi (bila diperlukan) terhadap laporan yang akan dikumpulan. 7) Laporan masing-masing siswa terhadap tugas-tugas yang telah dikumpulkan, disusun berkelompok kolaboratif. 8) Laporan siswa dikoreksi, dikomentari, dinilai, dikembalikan pada pertemuan berikutnya, dan didiskusikan.

Pembelajaran terbalik merupakan satu pendekatan terhadap pengajaran siswa akan strategistrategi belajar. Pengajaran terbalik adalah pendekatan konstruktivis yang berdasar pada prinsip-prinsip pembuatan / pengajuan pertanyaan. Teori konstruktivis menjelaskan bahwa guru tidak hanya sekedar memberikan pengetahuan kepada siswa tetapi juga memberikan kesempatan siswa untuk menemukan atau menerapkan ide-ide mereka sendiri dan mengajarkan siswa menjadi sadar menggunakan strategi mereka sendiri untuk belajar (Trianto, 2016). Dalam Pengajaran terbalik, guru mengajarkan siswa keterampilan kognitif penting dengan menciptakan pengalaman belajar, melalui pemodelan perilaku tertentu dan kemudian membantu siswa mengembangkan keterampilan tersebut atas usaha mereka sendiri dengan pemberian semangat, dukungan dan suatu sistem scaffolding (Trianto, 2016).
Kreativitas merupakan kemampuan seseorang untuk melahirkan sesuatu yang baru, baik berupa gagasan maupun karya nyata yang relatif berbeda dengan apa yang telah ada (Saripudin, 2017). Kreativitas masih dipandang sebagai bagian besar dari aktivitas dan produk dari bidang seni, meskipun kenyataannya, kreativitas bukan hanya dimiliki oleh para seniman belaka tetapi semua bidang membutuhkan kreativitas, termasuk dalam bidang pendidikan. Lembaga pendidikan memiliki peran penting dalam membangun kreativitas peserta didiknya para guru seharusnya dapat melakukan pembinaan kreativitas terhadap peserta didik jika para guru sudah membiasakan diri untuk memiliki sifat kreatif. Maka dari itu dalam proses pembelajaran dibutuhkan suatu cara/strategi yang dapat membantu menunjang kegiatan belajar mengajar agar tujuan pembelajaran dapat tercapai secara maksimal, karena kreativitas siswa dibutuhkan untuk menunjang proses pembelajaran.

Mata pelajaran ekonomi merupakan mata pelajaran yang ada disekolah tingkat SMA sederajat, didalamnya mempelajari tentang ilmu-ilmu ekonomi yang ada dilingkungan sekitar misalnya pemenuhan kebutuhan manusia dan peluang atau teori mikroekonomi, untuk menggali ilmu-ilmu tersebut perlu adanya observasi serta 
pengamatan yang mendalam tentu dengan adanya itu perlu seorang guru memilih metode yang tepat untuk menyampaikan ke peserta didik supaya ilmu yang disampaikan bisa diterima oleh peserta didik. Istilah ekonomi berasal dari bahasa yunani yaitu Oikonomia yang terdiri dari dua suku kata yaitu oikos dan nomos. Oikos berarti rumah tangga, sedangankan nomos berarti aturan. Sehingga mengandung arti aturan rumah tangga. Oikonomia mempunyai arti aturan yang berlaku untuk memenuhi kebutuhan hidup dalam suatu rumah tangga.

Kita sama-sama mengetahui praktik dilapangan seorang guru masih menggunakan metode ceramah dan tradisional. Maka dengan itu perlu diperbarui pola pikir seorang guru untuk mengembangkan metode yang baik untuk menyampaikan pembelajaran.

Didalam artikel ini membahas tentang pembaruan metode yang tepat untuk pembelajaran mata pelajaran ekonomi di tingkat SMA sederajat yaitu mengadopsi metode membalik kelas dengan menggunakan kreativitas siswa sebagai moderasi untuk menyempurnakan metode pembelajaran kolaboratif. Untuk mempermudah alur penelitian ini peneliti membuat kerangka pikir diatur oleh efek kontrol dari membalik kelas yang di moderasi oleh kreatifitas siswa seperti gambar 1. Dalam model penelitian ini kami akan menjelaskan latar belakang teoritis untuk hubungan antara variabel yang terkandung dalam penelitian. Dengan demikian kami memiliki hipotesis sementara yaitu sebagai berikut :

H1: Pembelajaran Kolaboratif memiliki berpengaruh signifikan terhadap membalik kelas.

H2: Kreativitas memiliki pengaruh positif dan memperkuat terhadap pembelajaran kolaboratif dan membalik kelas.

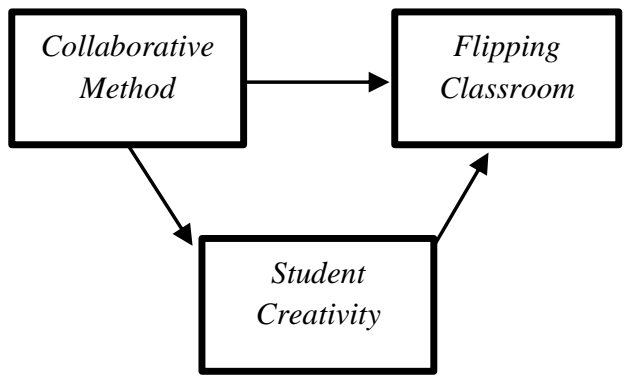

Gambar 1: Kerangka Penelitian Model di Moderasi (Sumber: Data Primer, 2021)

\section{METODE PENELITIAN}

Jenis penelitian yang digunakan dalam penelitian ini yaitu kuantitatif dengan menggunakan pendekatan moderasi atau analisis moderasi, dalam menentukan jumlah sampel penelitian ini menggunakan Nomogram Harry King. Penentuan sampel berdasarkan Nomogram Harry King adalah ukuran populasi maksimum 2000 dengan tingkat kesalahan bervariasi, mulai dari $0,3 \%$ hingga $15 \%$ dan faktor pengali disesuaikan untuk tingkat kesalahan yang ditentukan. Dengan populasi 
282 yang ditarik melalui tingkat kesalahan 5\% ditemukan titik dengan angka 35, untuk kesalahan 5\% berarti kepercayaan 95\% sehingga faktor pengali adalah 1,195. Maka jumlah sampel yang diambil adalah $0,35 \times 282 \times 1,195=117$ orang. Kemudian setiap sampel ditentukan menggunakan teknik Proportionate Random sampling, yaitu dengan memberikan peluang yang sama untuk setiap elemen (anggota) dari populasi untuk dipilih sebagai anggota sampel. Berdasarkan Nomogram Harry King, total 117 orang diproduksi, kemudian jumlah sampel yang mewakili siswa SMA Negeri 3 Yogyakarta Ekonomi menurut Proposiate Random Sampling adalah sebagai berikut tercantum dalam Tabel 1.

Tabel 1. Distribusi Sampel Penelitian.

\begin{tabular}{|c|c|c|}
\hline Kelas & Populasi & Sample \\
\hline X Ekonomi & 90 & $90 / 282 \times 117=37$ \\
\hline XI Ekonomi & 87 & $87 / 282 \times 117=36$ \\
\hline XII Ekonomi & 105 & $105 / 282 \times 117=44$ \\
\hline Total & 282 & 117 \\
\hline
\end{tabular}

Sumber: Diolah dari Hasil Penelitian, 2021

Teknik Pengumpulan Data dan Analisis Data

Analisis Regresi Moderasi (Moderating Regression Analysis)

Penelitian ini terdiri satu variabel independen, satu variabel dependen, dan satu variabel moderasi. Karena itulah digunakan moderating regression analysis. Analisis tersebut digunakan untuk melihat apakah variabel pemoderasi (XM) mempengaruhi pengaruh antara variabel $\mathrm{X}$ yaitu suatu variabel yang menekan/menerangkan variabel lainnya dan disebut sebagai variabel bebas (independen variabel) terhadap variabel $\mathrm{Y}$ (variabel dependen/terikat) yaitu: suatu variabel yang ditentukan atau diterangkan oleh variabel lainnya dari variabel ini

disebut dengan variabel tidak bebas (dependen variabel). Pengaruh ini selanjutnya dapat digunakan untuk mencari pengaruh variabel $\mathrm{X}$ terhadap variabel Y.

Kemudian melihat apakah variabel (XM) mempengaruhi hubungan antara variabel $\mathrm{X}$ terhadap Y. Moderating Regression Analysis dinyatakan dalam dua bentuk persamaan sebagai berikut :

Persamaan (1)

$\mathrm{Y}=\mathrm{a}+\mathrm{b} 1 \mathrm{x} 1$ 
Persamaan (2)

$\mathrm{Y}=\mathrm{a}+\mathrm{b} 1 \mathrm{x} 1+\mathrm{b} 2 \times 2+\mathrm{b} 3 \times 1 \times 2 \ldots(2)$

Pengujian secara simultan dimaksudkan apakah variabel bebas secara menyeluruh memberikan pengaruh nyata terhadap variabel terikat. Uji Hipotesis yang digunakan adalah uji F Hitung. F hitung dilakukan untuk mengetahui tingkat signifikan variabel independen secara bersama-sama terhadap variabel dependen. Tingkat signifikansi yang dipilih adalah 5\% $(\alpha=0,05)$ atau dengan tingkat kepercayaan sebesar $95 \%$ dari derajat $(\mathrm{dk})=\mathrm{n}-\mathrm{k}-1$. Angka ini dipilih tepat untuk mewakili dalam pengujian variabel dan merupakan tingkat signifikansi yang sering digunakan dalam penelitian. Kriteria pengambilan keputusan adalah $\mathrm{H} 0$ diterima bila : Fhitung $\leq$ Ftabel dan H0 ditolak bila : Fhitung $\geq$ Ftabel. Kaidah pengujian signifikansi dengan menggunakan program SPSS adalah:

a. Jika nilai probabilitas 0,05 lebih kecil atau sama dengan nilai probabilitas Sig atau $(0,05 \leq \mathrm{Sig})$, maka H0 diterima dan Ha ditolak, artinya tidak signifikan.

b. Jika nilai probabilitas 0,05 lebih besar atau sama dengan nilai probabilitas Sig atau $(0,05 \geq \mathrm{Sig})$, maka H0 ditolak dan Ha diterima, artinya signifikan.

\section{HASIL DAN PEMBAHASAN}

Penelitian terdahulu dari (Hastuti, 2020) menjelaskan yaitu salah satu bentuk pembelajaran yang mampu mengembangkan motivasi dan kemandirian belajar peserta didik adalah flipped learning dengan metode flipped classroom, pembelajaran ini dilaksanakan secara terbalik dengan memadukan pembelajaran secara daring dan juga tatap muka. Bentuk pembelajaran ini memungkinkan peserta didik dapat belajar secara efektif dan efesien, lebih mudah mengakses materi ajar, dan pada akhirnya meningkatkan motivasi dan kemandirian belajar peserta didik karena belajar dilakukan secara mandiri. Kemudian (Permana, 2020) mengemukkan dalam penelitiannya pembelajaran pada kelas campuran dengan metode membalik kelas dapat meningkatkan kompetensi belajar. Temuan ini merupakan pengembangan dari metode blended learning kelas flipped, metode pembelajaran yang dapat diterapkan dalam Blended themethod kelas flipped dapat digunakan sebagai referensi dalam pembelajaran baru.

Berbicara metode pemebelajaran menggunakan kreativitas (Rahmawati \& Yulianti, 2020) dalam penelitiannya menunjukkan bahwa pengajaran jarak jauh membutuhkan kerangka kerja yang praktis dan menarik agar siswa dapat berpartisipasi dalam pembelajaran dengan antusias. Pengajaran jarak jauh sangat efektif dan efisien namun guru memiliki keterbatasan dalam mengontrol nilai 
pendidikan karakter siswa secara langsung. (Suryani, 2010) menjelaskan pembelajaran kolaboratif sangat berfungsi untuk meningkatkan kemampuan siswa, merangsang pola pikir siswa. Pembelajaran kolaboratif juga mampu membuat siswa aktif seperti yang dijelaskan oleh (Layli, 2012) Model pembelajaran kolaboratif merupakan salah satu model pembelajaran yang diharapkan mampu mengefektifkan proses pembelajaran sehingga mampu membuat siswa lebih aktif dan kreatif.

Berdasarkan data yang diperoleh peneliti serta dianalisis menggunakan metode analisis regresi moderasi dan ditambah dengan hasil penelitian terdahulu dan teori-teori yang menjadi ajuan pedoman menghasilkan sebagai berikut dalam tabel di bawah :

Tabel 2. Output SPDD Pesamaan 1

Model Summary

\begin{tabular}{|c|c|c|c|c|}
\hline Model & R & R Square & Adjusted R Square & $\begin{array}{c}\text { Std. Error of the } \\
\text { Estimate }\end{array}$ \\
\hline 1 & $.140^{\mathrm{a}}$ & .020 & .011 & 1.82155 \\
\hline
\end{tabular}

a. Predictors: (Contant)

Sumber: Diolah dari Hasil Penelitian, 2021

Tabel 3. Output SPSS Persamaan 2

\begin{tabular}{|c|c|c|c|c|}
\hline Model & R & R Square & Adjusted R Square & $\begin{array}{c}\text { Std. Error of the } \\
\text { Estimate }\end{array}$ \\
\hline 1 & $.201^{\mathrm{a}}$ & .041 & .015 & 1.81786 \\
\hline
\end{tabular}

a. Predictors : (Contant), Pembelajaran

Sumber: Diolah dari Hasil Penelitian, 2021

Berdasarkan hasil persamaan regresi pertama pada tabel 1 model summary terdapat R2 sebesar 0,020 atau 20\% sedangkan setelah ada persamaan regresi kedua nilai R2 naik menjadi 0,041 atau $41 \%$ dengan melihat hasil diatas dapat disimpulkan bahwa dengan adanya kreativitas sebagai variabel moderasi akan dapat memperkuat hubungan metode membalik kelas dengan metode pembelajaran kolaboratif.
Sesuai dengan tujuan dari penelitian ini yaitu kami mengeksplorasi lebih lanjut pertanyaan yang diajukan oleh (Jensen et al., 2015) (Ryan \& Reid, 2015) serta membandingkan hasilnya mata kuliah prinsip mikroekonomi berbasis kuliah yang memanfaatkan teknik pembelajaran aktif dengan dua desain mata kuliah yang dibalik. Yang sesuai dengan pertanyaan penelitian ini adalah: (1) Bagaimana 
kedua desain kursus terbalik mempengaruhi hasil pembelajaran dan dibandingkan dengan kursus pembelajaran aktif yang tidak dibalik? (2) Bagaimana pengaruh kedua desain kursus terbalik tersebut terhadap evaluasi pembelajaran dan pengajaran yang dirasakan siswa (kepuasan, beban kerja, kesulitan yang dirasakan) dibandingkan dengan kursus pembelajaran aktif yang tidak dibalik?.

Dengan begitu penelitian ini memperlemah atau memperkuat penelitian dari penelitian terdahulu akan tetapi ada pembaharuan dimana dalam penelitian ini ada penambahan variabel moderasi didalam judul penelitian. Hasil analisis membuktikan bahwa pembelajaran kolaboratif atau variabel $\mathrm{X}$ tidak berpengaruh signifikan terhadap variabel Y atau membalik kelas. Hal tersebut menunjukan bahwa pembelajaran kolaboratif tidak pengaruh terhadap membalik kelas (H-1). selanjutnya, berdasarkan hasil analisis pembelajaran kolaboratif variabel $\mathrm{X}$ terhadap variabel $\mathrm{Y}$ atau membalik kelas terdapat signifikan 0.9 setelah dimoderasi oleh variabel kreativitas. hal tersebut menunjukkan Kreativitas memiliki pengaruh positif dan memperkuat terhadap pembelajaran kolaboratif dan membalik kelas (H-2). Hasil ini menunjukan bahwa semakin tinggi kreatifitas maka semakin baik proses pembelajaran dengan menggunakan pembelajaran kolaboratif dan membalik kelas.

\section{KESIMPULAN}

Dalam penelitian ini ada pembaruan data hasil analisis membuktikan bahwa pembelajaran kolaboratif atau variabel $\mathrm{X}$ tidak berpengaruh signifikan terhadap variabel Y atau membalik kelas. Hal tersebut menunjukan bahwa pembelajaran kolaboratif tidak pengaruh terhadap membalik kelas (H-1). selanjutnya, berdasarkan hasil analisis pembelajaran kolaboratif variabel $\mathrm{X}$ terhadap variabel $\mathrm{Y}$ atau membalik kelas terdapat signifikan 0.9 setelah dimoderasi oleh variabel kreativitas. hal tersebut menunjukkan Kreativitas memiliki pengaruh positif dan memperkuat terhadap pembelajaran kolaboratif dan membalik kelas (H-2). Hasil ini menunjukan bahwa semakin tinggi kreatifitas maka semakin baik proses pembelajaran dengan menggunakan pembelajaran kolaboratif dan membalik kelas.

\section{DAFTAR PUSTAKA}

Bishop, J. L., \& Verleger, M. A. (2013). The flipped classroom: A survey of the research. ASEE Annual Conference and Exposition, Conference Proceedings. https://doi.org/10.18260/1-2-22585

Freeman, S., Eddy, S. L., McDonough, M., Smith, M. K., Okoroafor, N., Jordt, H., \& Wenderoth, M. P. (2014). 
Active learning increases student performance in science, engineering, and mathematics. Proceedings of the National Academy of Sciences of the United States of America, 111(23), $\quad$ 8410-8415. https://doi.org/10.1073/pnas.13 19030111

Hastuti, W. D. (2020). Membangun Motivasi dan Kemandirian Peserta Didik Berkebutuhan Khusus Melalui Flipped Classroom di Masa New Normal Covid-19. Prosiding Webinar Magister Pendidikan Nonformal UNG | 181, September, 181-192.

Hosnan, M. (2014). Pendekatan Saintifik dan Kontekstual Dalam Pembelajaran Abad 21: Kunci Sukses Implementasi Kurikulum 2013.

Jensen, J. L., Kummer, T. A., \& Godoy, P. D. d. M. (2015). Improvements from a Flipped Classroom May Simply Be the Fruits of Active Learning. CBE Life Sciences Education, 14(1), $1-12$.

https://doi.org/10.1187/CBE.14 $-08-0129$

Layli, N. (2012). Pembelajaran Kolaboratif Pada Dalam Mata Pelajaran Ilmu Pengetahuan Sosial Terpadu. Solidarity: Journal of Education, Society and Culture, 1(1).

O'Flaherty, J., Phillips, C., Karanicolas, S., Snelling, C., \& Winning, T. (2015). Erratum: The use of flipped classrooms in higher education: A scoping review (The Internet and Higher Education (2015) 25 (85-95)). Internet and Higher
Education, $27, \quad 90$. https://doi.org/10.1016/j.iheduc. 2015.05.001

Permana, R. (2020). Mengkaji Penerapan Blended Learning Menggunakan Metode Flipped Classroom di Perguruan Tinggi Agama Kristen. Jurnal Teruna Bhakti, 2(2), 112. https://doi.org/10.47131/jtb.v2i 2.44

Rahmawati, I. Y., \& Yulianti, B. (2020). Kreativitas guru dalam proses pembelajaran ditinjau dari penggunaan metode pembelajaran jarak jauh di tengah wabah. ALASASIYYA: Journal Basic of Education, 5(1), 27-39. http://journal.umpo.ac.id/index. php/al-asasiyya/index

Ryan, M. D., \& Reid, S. A. (2015). Impact of the Flipped Classroom on Student Performance and Retention: A Parallel Controlled Study in General Chemistry. Journal of Chemical Education, 93(1), 1323.

https://doi.org/10.1021/ACS.JC HEMED.5B00717

Saripudin, A. (2017). Strategi Pengembangan Kecerdasan Naturalis Pada Anak Usia Dini. AWLADY : Jurnal Pendidikan Anak, 3(1). https://doi.org/10.24235/awlady .v3i1.1394

Sudrajat, Y. (2020). Implementasi Pembelajaran Aktif (Active Learning) Untuk Meningkatkan Kompetensi Spiritual Dan Sosial Siswa Dalam Pembelajaran Pendidikan Pancasila. Academy of Education Journal, 11(2), 142- 
167.

https://doi.org/10.47200/aoej.v1 $1 \mathrm{i} 2.398$

Suryani, N. (2010). Implementasi

Model Pembelajaran

Kolaboratif Untuk

Meningkatkan Ketrampilan

Sosial Siswa. Majalah Ilmiah

Pembelajaran, 8(2).

Trianto. (2016). Desain

Pengembangan Pembelajaran

Tematik: Bagi anak Usia Dini.

In J. Alfin (Ed.), Media Pradana

(1st ed.).

https://books.google.co.id/book

s?id=LFFADwAAQBAJ

Watts, M., \& Schaur, G. (2011). Teaching and assessment methods in undergraduate economics: A fourth national quinquennial survey. Journal of Economic Education, 42(3), 294-309.

https://doi.org/10.1080/002204

85.2011 .581956 